\title{
A Comprehensive Study of Channel Equalization Techniques in MIMO-OFDM Systems
}

\author{
Lipsa Dash ${ }^{1}$, Sree Ramani Potluri ${ }^{2}$ \\ Asst. Prof, Department of ECE, New Horizon College of Engineering, Bangalore ${ }^{1}$ \\ Sr. Asst. Prof, Department of ECE, New Horizon College of Engineering, Bangalore ${ }^{2}$
}

\begin{abstract}
Today's communication scenario demands high data rates and large system capacity where MIMO-OFDM proves to be an ultimate combination. The never ending thirst for such high performance wireless communication results in signal vulnerability to channel impairments. One of the primary causes resulting in signal degradation due to the multipath propagation is channel ISI (Inter symbol interference). The process of channel estimation and equalization together accomplishes the job of combating the effect of ISI. Initially CIR(Channel Impulse Response) is estimated based on a known sequence of bits(Pilot sequence) followed by equalization process which takes care of altering the channel response based on the estimated behavior thereby extracting the signal of interest. It is also possible to implement non pilot aided approaches like blind channel equalizer algorithms without possessing knowledge of the channel. This paper does a comprehensive survey of different types of equalizers thereby providing an in depth understanding of equalization.
\end{abstract}

Keywords: MIMO, OFDM, ISI, ICI, CSI, MMSE.

\section{INTRODUCTION}

The major goal of wireless communication is to provide high data rate multimedia applications. When data is transmitted at high rates over radio link the CIR can extend to several symbol periods due to the multipath signal propagation phenomena resulting in Inter Symbol Interference. MIMO (Multiple Input Multiple Output) exploits multipath propagation signals by sending and receiving more than one data signal in the same frequency band at the same time by implementing transmit and receive diversity thereby increasing the channel capacity multiple times. OFDM (Orthogonal Frequency Division Multiplexing) is one of the shining candidates in handling the effect of ISI [1] [2]. It converts the frequency selective wide band signal into frequency flat multiple orthogonally spaced narrow band signals resulting in high bandwidth efficiency. While OFDM systems have strong immunity to time-invariant frequency selective multipath fading channels with the help of guard band it suffers severely from time varying channels mainly due to user's mobility. Rapid channel variation over symbol duration destroys the orthogonality among subcarriers and gives rise to ICI (Inter Channel Interference) .To Suppress ICI effectively for high performing coherent detection, CSI (Channel State Information) is indispensable. Channel estimation hence can be roughly divided into two categories: one employing a transmitted reference commonly known as pilot symbol assisted modulation, the other is blind channel estimation.

In most MIMO-OFDM systems, the precise knowledge of the CSI is critical to equalization algorithms, the performance of MIMO-OFDM systems grows linearly with precise channel estimation [3]. Broadly speaking, MIMO-OFDM channel estimation methods can be categorized into three classes, training sequence [4], blind and semi blind approaches [5].

\section{SIGNIFICANCE OF EQUALIZATION}

Equalization techniques play an indispensable role in the design of high data rate wireless Systems. Equalizer situated at the receiver side compensates for the average range of expected channel amplitude and delay characteristics. It is usually a filter which updates its weights (taps) according to the channel coefficients with the help of equalization algorithms in order to minimize the overall bit error rate thereby improving SNR. The equalizer is placed at receiver front end having a transfer function which is inverse of the channel transfer function [6]. It is an iterative process of reducing the mean square error and could be performed in both time and frequency domains. The equalizer finds the error difference by subtracting the desired output from the actual estimated one and uses this difference in updating the filter coefficients (tap weights) to minimize the error and to equalize distortions. The coefficients are updated using adaptive algorithms [7]. The adaptive equalizers are broadly classified into two types based on the presence of feedback path: Linear equalizer and Non-linear equalizer

The linear equalizers do not employ a feedback path to adapt the equalizer and therefore, provide simpler implementations whereas in nonlinear equalizer the output is fed back to input in order to change the subsequent outputs of the equalizer and are widely employed in wireless applications where the channel distortions are too critical for a linear equalizer to manage [8].

\section{TYPES OF EQUALIZERS}

\section{A. Zero Forcing Equalizer (ZFE)}

It is a form of linear equalizer which applies the inverse of the frequency response of the channel [16]. It is named so as it is used to bring down the ISI to zero in a noise free case. It aims to eliminate ISI at decision time instants i.e. 
at the centre of the bit/symbol interval [9][10].

For a 2 × 2 MIMO channel the received signal is given by

$$
\left[\begin{array}{l}
y_{1} \\
y_{2}
\end{array}\right]=\left[\begin{array}{ll}
h_{1,1} & h_{1,2} \\
h_{2,1} & h_{2,2}
\end{array}\right]\left[\begin{array}{l}
x_{1} \\
x_{2}
\end{array}\right]+\left[\begin{array}{l}
n_{1} \\
n_{2}
\end{array}\right] .
$$

In matrix form,

$$
\mathrm{y}=\mathrm{Hx}+\mathrm{n}
$$

To solve for $\mathrm{x}$ we need to find matrix $\mathrm{W}$ which satisfies the condition,

$$
\mathrm{WH}=\mathrm{I}
$$

The zero forcing detector for meeting this condition is given by

$$
\mathrm{W}=\left(\mathrm{H}^{\mathrm{H}} \mathrm{H}\right)^{-1} \mathrm{H}^{\mathrm{H}}
$$

Where $\mathrm{W}$ is equalization matrix and $\mathrm{H}$ is channel matrix.

\section{B. Minimum Mean Square Error (MMSE)}

This estimator minimizes the mean square error (MSE), which is a common measure of estimator quality [8][7][9].The MMSE tries to find a coefficient W which minimizes

$$
E\left\{\left[w_{y}-x\right]\left[w_{y}-x\right]^{H}\right\}
$$

A matrix which satisfies MMSE detector for meeting this constraint is given by

$$
\mathrm{W}=\left[\mathrm{H}^{\mathrm{H}} \mathrm{H}+\mathrm{N}_{0} \mathrm{I}\right]^{-1} \mathrm{H}^{\mathrm{H}}
$$

Apart from the NOI term the equations for ZF and MMSE are exactly same which indicates that in absence of noise MMSE equalizer reduces to Zero Forcing equalizer.

\section{Fractionally Spaced Equalizer (FSE)}

It is based on sampling the incoming signal at least as fast as the Nyquist rate. These equalizers have taps that are spaced closer than conventional adaptive equalizers with a sufficient number of taps. It can negate the channel distortion without enhancing the noise hence is said to be almost independent of channel delay distortion [10]. Although FSE requires increased complexity to implement, its ability to effectively compensate for an extremely wide range of delay distortion is a major feature that surpasses the complexity disadvantage.

\section{Decision Feedback Equalization (DFE):}

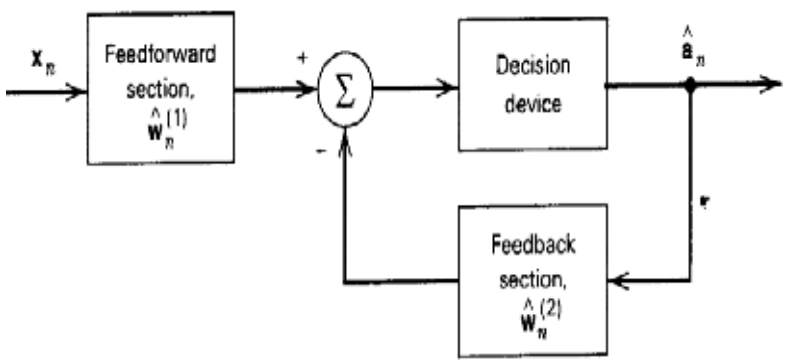

Fig.1 Block diagram of a decision feedback equalizer.

It augments a linear equalizer by adding a filtered version of previous symbol estimates to the original filter output. DFE allows a window of ISI to pass from feed-forward filter, while attempting to minimize the rest of ISI.
Window of ISI is then subtracted by means of a feedback filter. This technique results in a distortion less transmission. Initially training symbols which are known by the receiver are transmitted [12].The difference between the desired and recovered symbol is known as error which is used to update the feed-forward and feedback filter. In the beginning error is large but in course of time the error reduces and finally becomes approximately equal to zero.

\section{E. Maximum Likelihood Sequence Estimator (MLSE)}

MLSE tests all possible data sequences rather than decoding each received symbol by itself, and chooses the data sequence with the maximum probability as the output .Usually it has a large computational requirement. MLSE requires knowledge of the channel characteristics in order to compute the metrics for making decisions and also the knowledge of the statistical distribution of the noise corrupting the signal.

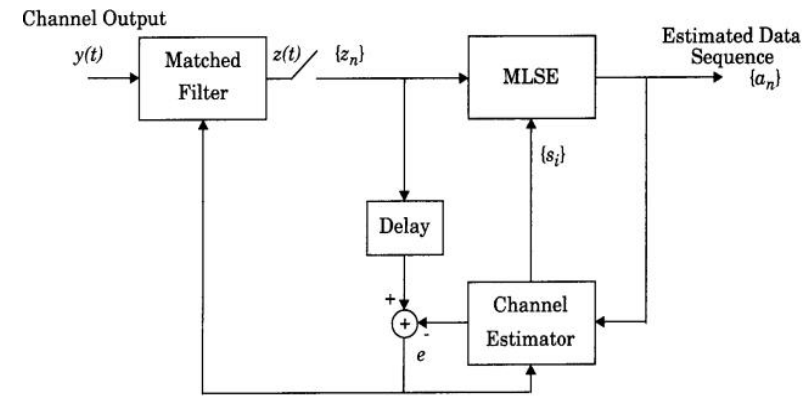

Fig.2 Structure of MLSE with an adaptive matched filter.

\section{F. Maximal-Ratio Combining Equalizer(MRC):}

Maximal-ratio combining is a method of diversity combining in which the signals from each channel are added together [18]. The gain of each channel is made proportional to the RMS signal level and inversely proportional to the mean square noise level in that channel. Different proportionality constants are used for each channel. It is the optimum combiner for independent AWGN channels.

\section{G. Successive Interference Cancellation (SIC):}

When signals are detected successively, the earlier resulted symbols of the detectors are used to determine the behavior of next symbols, which is a kind of decision directed detection [17]. As the first bit is detected by the de-correlation, supposing the result of first detected bit to be correct, it is used to cancel the interference from the next following signal vector being received.

The estimate of the two transmitted symbols $X_{1}$ and $X_{2}$ by the receiver is calculated as

$$
\left[\begin{array}{l}
\hat{x}_{1} \\
\hat{x}_{2}
\end{array}\right]=\left(H^{H} H\right)^{-1} H^{H}\left[\begin{array}{l}
y_{1} \\
y_{2}
\end{array}\right]
$$

One estimated signal is taken at one time and its effect is subtracted from the received vector $\mathrm{Y}_{1}$ and $\mathrm{Y}_{2}$.

$$
\left[\begin{array}{l}
r_{1} \\
r_{2}
\end{array}\right]=\left[\begin{array}{ll}
y_{1} & -h_{1,2} \hat{x}_{2} \\
y_{2} & -h_{2,2} \hat{x}_{2}
\end{array}\right]=\left[\begin{array}{ll}
h_{1,1} x_{1} & +n_{1} \\
h_{2,1} x_{1} & +n_{2}
\end{array}\right]
$$

The detected SIC signal $\mathrm{S}=\mathrm{W}_{\text {SIC }} \cdot \mathrm{y}$ 
Modified received signal is $\mathrm{y}-\mathrm{s}$. $(\mathrm{H})_{1}$ Where $(\mathrm{H})_{1}$ signify the first column of $\mathrm{H}$. The operation is repeated until all bits are detected. The first row of $\mathrm{H}$ is of no use once detected and hence is removed.

\section{LITERATURE REVIEW}

\begin{tabular}{|c|c|c|}
\hline Author & $\begin{array}{c}\text { Research } \\
\text { methodology }\end{array}$ & Conclusion \\
\hline $\begin{array}{l}\text { Gong } \\
\text { Guoqiang, } \\
\text { Xia Ping } \\
{[11]}\end{array}$ & $\begin{array}{l}\text { The authors } \\
\text { proposed an } \\
\text { iterative MAP- } \\
\text { MMSE algorithm } \\
\text { using soft decision } \\
\text { signals, pilots to } \\
\text { renew channel } \\
\text { estimation thereby } \\
\text { subtracting ICI to } \\
\text { obtain a simple } \\
\text { Turbo equalization } \\
\text { algorithm having } \\
\text { lower complexity } \\
\text { than traditional } \\
\text { algorithms. }\end{array}$ & $\begin{array}{l}\text { It is concluded that } \\
\text { the iterative BER } \\
\text { when mobile speed } \\
\text { is } 180 \mathrm{~km} / \mathrm{h} \text {, } \\
\text { reaches below } 10-5 \\
\text { at } \mathrm{SNR} \text { of } 17.5 \mathrm{~dB} \\
\text { compared to no } \\
\text { iterative situation } \\
\text { where MMSE is } \\
\text { more optimal than } \\
\text { basis expansion } \\
\text { (BE) model. }\end{array}$ \\
\hline $\begin{array}{l}\text { Atapattu, } \\
\text { Hajime, } \\
\text { Dhammika } \\
{[8]}\end{array}$ & $\begin{array}{l}\text { This paper } \\
\text { presented a linear } \\
\text { adaptive } \\
\text { equalization } \\
\text { approach } \\
\text { using LMS and } \\
\text { RLS adaptive } \\
\text { algorithms for MU- } \\
\text { MIMO OFDM } \\
\text { Systems that can } \\
\text { adaptively equalize } \\
\text { the channel } \\
\text { impairments. }\end{array}$ & $\begin{array}{l}\text { The proposed } \\
\text { paper showed an } \\
\text { improvement of } \\
0.15 \text { in BER (at a } \\
\text { SNR of } 16 \mathrm{~dB} \text { ) } \\
\text { when using } \\
\text { Adaptive } \\
\text { Equalization and } \\
\text { RLS algorithm } \\
\text { compared to the } \\
\text { case in which no } \\
\text { equalization is } \\
\text { employed. }\end{array}$ \\
\hline $\begin{array}{l}\text { Darsena, } \\
\text { Vitiello } \\
{[12]}\end{array}$ & $\begin{array}{l}\text { The authors } \\
\text { propose an } \\
\text { improved linear } \mathrm{ZF} \\
\text { equalizer, which } \\
\text { mitigates the } \\
\text { impulse noise } \\
\text { contribution in the } \\
\text { minimum mean } \\
\text { output-energy } \\
\text { (MMOE) sense at } \\
\text { the equalizer } \\
\text { output. }\end{array}$ & $\begin{array}{l}\text { Results have } \\
\text { shown that the } \\
\text { proposed } \\
\text { receiver } \\
\text { outperforms } \\
\text { existing } \\
\text { approaches in } \\
\text { presence of high } \\
\text { spatial correlation } \\
\text { between noise } \\
\text { samples and is } \\
\text { more pronounced } \\
\text { for higher } \\
\text { cardinality } \\
\text { constellations such } \\
\text { as 16-QAM. }\end{array}$ \\
\hline $\begin{array}{l}\text { Chaudhary, } \\
\text { Madhavi } \\
\text { Pradeep } \\
{[13]}\end{array}$ & $\begin{array}{l}\text { BER performance } \\
\text { improvements of } \\
\text { MIMO-OFDM } \\
\text { systems using } \\
\text { different } \\
\text { equalization } \\
\text { techniques such as } \\
\text { Zero forcing (ZF), } \\
\text { Minimum mean } \\
\text { square error }\end{array}$ & $\begin{array}{l}\text { It is concluded that } \\
\text { BPSK shows better } \\
\text { performance as } \\
\text { compared to QPSK } \\
\text { for both } \mathrm{ZF} \text { and } \\
\text { MMSE. } \\
\text { An overall overall } \\
\text { gain of } 4 \mathrm{~dB} \text { is } \\
\text { obtained using ML } \\
\text { and } \mathrm{ZF} \text { and } 5\end{array}$ \\
\hline
\end{tabular}

\begin{tabular}{|c|c|c|}
\hline & $\begin{array}{l}\text { (MMSE) and } \\
\text { Maximum } \\
\text { likelihood (ML) } \\
\text { are analyzed and } \\
\text { compared under } \\
\text { Rayleigh frequency } \\
\text { flat channels. }\end{array}$ & $\begin{array}{l}\text { dB using MMSE at } \\
\text { BER of } 10.3 \text {. }\end{array}$ \\
\hline $\begin{array}{l}\text { Chen, } \\
\text { Chang, } \\
\text { Yang } \\
{[14]}\end{array}$ & $\begin{array}{l}\text { A low-complexity } \\
\text { turbo equalization } \\
\text { algorithm was } \\
\text { proposed for } \\
\text { MIMO-OFDM } \\
\text { system without } \\
\text { CP(Cyclic Prefix). }\end{array}$ & $\begin{array}{l}\text { The proposed } \\
\text { algorithm achieves } \\
\text { better trade-off } \\
\text { between BER } \\
\text { performance and } \\
\text { computational } \\
\text { complexity } \\
\text { compared to } \\
\text { existing algorithms } \\
\text { by implementing } \\
\text { tail cancellation, } \\
\text { cyclic restoration } \\
\text { and CAI } \\
\text { cancellation to } \\
\text { suppress IBI( inter } \\
\text { block interference), } \\
\text { ICI and CAI } \\
\text { (co-antenna } \\
\text { interference) } \\
\text { respectively. }\end{array}$ \\
\hline $\begin{array}{l}\text { Dhiwer, } \\
\text { Mandal } \\
{[15]}\end{array}$ & $\begin{array}{l}\text { A } 2 \text { X2 MIMO } \\
\text { system was } \\
\text { designed and } \\
\text { different } \\
\text { equalization } \\
\text { algorithms such as } \\
\text { ZF, MMSE, ZFPIC } \\
\text { and ML were } \\
\text { implemented. }\end{array}$ & $\begin{array}{l}\text { It is observed that } \\
\text { MMSE is giving } \\
\text { 3dB SNR } \\
\text { improvement } \\
\text { compared to ZF } \\
\text { and among all } \\
\text { Maximum } \\
\text { Likelihood } \\
\text { technique gives } \\
\text { best performance } \\
\text { by } 2.2 \text { dB } \\
\text { compared to ZF } \\
\text { with Parallel } \\
\text { interference } \\
\text { cancellation. }\end{array}$ \\
\hline
\end{tabular}

\section{CONCLUSION}

This paper gives a basic understanding of equalization process, discusses its significance in a communication system. Different types of equalization highlighted in the paper serves a basis for the design of the equalizer unit. A review of various existing work, methodologies used and approaches of designing an equalizer is carried out. In spite of many contributions, this area still attracts many researchers to think upon different schemes and algorithms to reduce the system complexity thereby achieving high system performance.

\section{REFERENCES}

[1] D. Tse and P. Viswanath, Fundamentals of Wireless Communication, Cambridge University Press, 2005.

[2] Z. Wang and G. B. Giannakis, "Wireless multicarrier communications- Where Fourier meets Shannon," IEEE Signal Processing Magazine, vol. 17, no. 3, pp. 29-48, May 2000

[3] Fei F. Cao, Jiangdong Li, and Guanghui Yu, "High-performance Detection Algorithm for MIMO-OFDM in Doubly Selective 
Channels", IEICE Electronics Express, Vol. 7, No. 7, January, 2010, pp. 487-492.

[4] Giulio C., Erwin R., et al., "Optimum MIMO-OFDM Detection With Pilot-Aided Channel State Information", IEEE Journal of Selected Topics in Signal Processing, Vol. 3, No. 6, December, 2009, pp. 1053-1064.

[5] Jung-lang Yu, Yin-cheng Lin, "Space-time-coded MIMO ZPOFDM Systems: Semiblind Channel Estimation and Equalization", IEEE Trans.+On Circuits and Systems, Vol. 56, No. 7, July, 2009, pp. 1360-1372.

[6] Chan, Albert M.; Gregory W. Wornell, "A class of block-iterative equalizers for intersymbol interference channels", In Communications, ICC 2000, IEEE International Conference on, vol. 1, pp. 31-35, 2000

[7] Yong-Soo Cho, Won-Gi Jeon, "An equalization technique for orthogonal frequency-division multiplexing systems in time-variant multipath channels, " IEEE, vol. 47, no. 1, pp. 27-32, Jan 1999.

[8] Lakmali Atapattu, Gayan Munasinghe Arachchige, Karla Ziri Castro, Hajime Suzuki and Dhammika Jayalath," Linear Adaptive Channel Equalization for Multiuser MIMO-OFDM Systems", IEEE, 2012

[9] Vinay Dawar, Ritu Sharma"Reduction in Bit Error Rate from Various Equalization Techniques for MIMO Technology" IJSCE ISSN: 2231-2307, Volume-2, Issue-4, September 201266

[10] Navdeep Singh Randhawa, Silky Khurana" Error Rate Performance Enhancement Using Hybrid Equalization technique in MIMOOFDM systems, presented in IEEE conference, ICHPCA, 22 -24 Dec. 2014.

[11] Gong Guoqiang, Xia Ping "Iterative Channel Estimation and Turbo Equalization Using ICI Cancellation for MIMO-OFDM Systems"2013 IEEE.

[12] Xiao Ying; Li Chun-Jie, "Blind adaptive decision feedback equalization algorithm correct by instantaneous error", International Conference on Signal Processing Systems (ICSPS), Vol: 2, Page: V2-609 - V2-612, 2010

[13] Shubhangi R.Chaudhary, Madhavi Pradeep Thombre" BER Performance Analysis of MIMO-OFDM System Using Different Equalization Techniques"2014 IEEE International Conference on Advanced Communication Control and Computing Technologies (ICACCCT).

[14] Zhe Chen, Chang Yongyu and Dacheng Yang "Low-Complexity Turbo Equalization for MIMOOFDM System without Cyclic Prefix", 2009 IEEE.

[15] Yashvant Dhiwer, Rakesh Mandal "Performance Analysis of Various Equalizers for ISI reduction in MIMO-OFDM system" International Journal of Research in Advent Technology, Vol.2, No.3, March 2014.

[16] Parul Wadhwa ,Gaurav Gupta" BER Analysis \& Comparison of Different Equalization Techniques for MIMO-OFDM System" Volume 3, Issue 6, June 2013 International Journal of Advanced Research in Computer Science and Software Engineering.

[17] Hyuncheol Park, Kwanghoon Kim, "Modified Successive Interference Cancellation for MIMO OFDM on Doubly Selective Channels, " IEEE, vol., no., pp. 1, 5, 26-29 April 2009.

[18] Lopez-Martinez, Martos-Naya, E., Goldsmith, "BER Analysis for MIMO-OFDM Beam forming with MRC under Channel Prediction and Interpolation Errors," Global Telecommunications Conference, IEEE, vol., no., pp. 1-7, Nov. 30 2009-Dec. 42009. 